\title{
High-dose chemotherapy followed by autologous haematopoietic cell transplantation for children, adolescents, and young adults with first recurrence of Ewing sarcoma
}

\author{
Haveman, Lianne M ; van Ewijk, Roelof ; van Dalen, Elvira C ; Breunis, Willemijn B ; Kremer, \\ Leontien C M ; van den Berg, Henk ; Dirksen, Uta ; Merks, Johannes H M
}

\begin{abstract}
BACKGROUND Ewing sarcoma is a solid tumour, which is the second most common primary bone malignancy in children, often occurring in the long bones and pelvis. An incidence rate of 4.5 per million a year is reported, with a peak incidence of 11 per million at the age of 12 years. Despite more intensive chemotherapy, 30\% to $40 \%$ of young people with Ewing sarcoma will have recurrence of the disease. Less than $30 \%$ of young people with a recurrence of Ewing sarcoma are alive at 24 months, and less than $10 \%$ are alive at 48 months. High-dose chemotherapy (HDC), followed by autologous haematopoietic cell transplantation (AHCT), is used in a variety of paediatric groups with diverse solid tumours. The hypothesis is that HDC regimens may overcome resistance to standard polychemotherapy, and this way may eradicate minimal residual disease, leading to improved survival after a first recurrence of disease. OBJECTIVES To assess the efficacy of HDC with AHCT versus conventional chemotherapy in improving event-free survival, overall survival, quality-adjusted survival, and progression-free survival in children, adolescents, and young adults with first recurrence of Ewing sarcoma, and to determine the toxicity of the treatment. SEARCH METHODS We searched CENTRAL, MEDLINE, Embase, conference proceedings from the SIOP, ASPHO, CTOS, ASBMT, EBMT, and EMSOS, and two trial registries in January 2020. We also searched reference lists of relevant articles and review articles. SELECTION CRITERIA We planned to include randomised controlled trials (RCTs) or (historical) controlled clinical trials (CCTs) comparing the effectiveness of HDC plus AHCT with conventional chemotherapy for children, adolescents, and young adults (up to 30 years old at the date of diagnostic biopsy) with a first recurrence of Ewing sarcoma. DATA COLLECTION AND ANALYSIS We used standard methodological procedures expected by Cochrane. MAIN RESULTS We did not identify any eligible studies. AUTHORS' CONCLUSIONS Since we did not identify any eligible studies, we are unable to draw any conclusions about the efficacy and toxicity of HDC with AHCT versus conventional chemotherapy in children, adolescents, and young adults with a first recurrence of Ewing sarcoma. Further high-quality research is urgently needed.
\end{abstract}

DOI: https://doi.org/10.1002/14651858.CD011406.pub2

Posted at the Zurich Open Repository and Archive, University of Zurich

ZORA URL: https://doi.org/10.5167/uzh-212918

Journal Article

Published Version

Originally published at:

Haveman, Lianne M; van Ewijk, Roelof; van Dalen, Elvira C; Breunis, Willemijn B; Kremer, Leontien C M; van den Berg, Henk; Dirksen, Uta; Merks, Johannes H M (2021). High-dose chemotherapy followed 
by autologous haematopoietic cell transplantation for children, adolescents, and young adults with first recurrence of Ewing sarcoma. Cochrane Database of Systematic Reviews, 9:CD011406.

DOI: https://doi.org/10.1002/14651858.CD011406.pub2 


\section{High-dose chemotherapy followed by autologous haematopoietic cell transplantation for children, adolescents, and young adults with first recurrence of Ewing sarcoma (Review)}

Haveman LM, van Ewijk R, van Dalen EC, Breunis WB, Kremer LCM, van den Berg H, Dirksen U, Merks JHM

Haveman LM, van Ewijk R, van Dalen EC, Breunis WB, Kremer LCM, van den Berg H, Dirksen U, Merks JHM.

High-dose chemotherapy followed by autologous haematopoietic cell transplantation for children, adolescents, and young adults with first recurrence of Ewing sarcoma.

Cochrane Database of Systematic Reviews 2021, Issue 9. Art. No.: CD011406.

DOI: 10.1002/14651858.CD011406.pub2. 
ABSTRACT 1

PLAIN LANGUAGE SUMMARY

SUMMARY OF FINDINGS

BACKGROUND

OBJECTIVES

METHODS

Figure 1.

RESULTS

DISCUSSION

AUTHORS' CONCLUSIONS

ACKNOWLEDGEMENTS

REFERENCES

CHARACTERISTICS OF STUDIES

APPENDICES

HISTORY

CONTRIBUTIONS OF AUTHORS

DECLARATIONS OF INTEREST

SOURCES OF SUPPORT

DIFFERENCES BETWEEN PROTOCOL AND REVIEW

INDEX TERMS

\section{TABLE OF CONTENTS}


[Intervention Review]

\section{High-dose chemotherapy followed by autologous haematopoietic cell transplantation for children, adolescents, and young adults with first recurrence of Ewing sarcoma}

Lianne M Haveman ${ }^{1 a}$, Roelof van Ewijk ${ }^{1}$, Elvira C van Dalen¹, Willemijn B Breunis2,3, Leontien CM Kremer ${ }^{1,2}$, Henk van den Berg2 ${ }^{2}$ Uta Dirksen 4 , Johannes HM Merks $1,2 b$

1Princess Máxima Center for Pediatric Oncology, Utrecht, Netherlands. 2Department of Paediatric Oncology, Emma Children's Hospital, Amsterdam UMC, University of Amsterdam, Amsterdam, Netherlands. ${ }^{3}$ Department of Oncology and Children's Research Center, University Children's Hospital Zurich, Zurich, Switzerland. ${ }^{4}$ Pediatrics III, Sarcoma Centre, West German Cancer Centre, University Hospital Essen, Essen, Germany

a Joint first authorship with Roelof van Ewijk. b Joint last authorship with Uta Dirksen

Contact: Lianne M Haveman, I.m.haveman-3@prinsesmaximacentrum.nl.

Editorial group: Cochrane Childhood Cancer Group.

Publication status and date: New, published in Issue 9, 2021.

Citation: Haveman LM, van Ewijk R, van Dalen EC, Breunis WB, Kremer LCM, van den Berg H, Dirksen U, Merks JHM. Highdose chemotherapy followed by autologous haematopoietic cell transplantation for children, adolescents, and young adults with first recurrence of Ewing sarcoma. Cochrane Database of Systematic Reviews 2021, Issue 9. Art. No.: CD011406. DOI: 10.1002/14651858.CD011406.pub2.

Copyright @ 2021 The Cochrane Collaboration. Published by John Wiley \& Sons, Ltd.

\section{A B S T R A C T}

\section{Background}

Ewing sarcoma is a solid tumour, which is the second most common primary bone malignancy in children, often occurring in the long bones and pelvis. An incidence rate of 4.5 per million a year is reported, with a peak incidence of 11 per million at the age of 12 years. Despite more intensive chemotherapy, $30 \%$ to $40 \%$ of young people with Ewing sarcoma will have recurrence of the disease. Less than $30 \%$ of young people with a recurrence of Ewing sarcoma are alive at 24 months, and less than $10 \%$ are alive at 48 months. High-dose chemotherapy (HDC), followed by autologous haematopoietic cell transplantation (AHCT), is used in a variety of paediatric groups with diverse solid tumours. The hypothesis is that HDC regimens may overcome resistance to standard polychemotherapy, and this way may eradicate minimal residual disease, leading to improved survival after a first recurrence of disease.

\section{Objectives}

To assess the efficacy of HDC with AHCT versus conventional chemotherapy in improving event-free survival, overall survival, qualityadjusted survival, and progression-free survival in children, adolescents, and young adults with first recurrence of Ewing sarcoma, and to determine the toxicity of the treatment.

\section{Search methods}

We searched CENTRAL, MEDLINE, Embase, conference proceedings from the SIOP, ASPHO, CTOS, ASBMT, EBMT, and EMSOS, and two trial registries in January 2020. We also searched reference lists of relevant articles and review articles.

\section{Selection criteria}

We planned to include randomised controlled trials (RCTs) or (historical) controlled clinical trials (CCTs) comparing the effectiveness of HDC plus AHCT with conventional chemotherapy for children, adolescents, and young adults (up to 30 years old at the date of diagnostic biopsy) with a first recurrence of Ewing sarcoma. 


\section{Data collection and analysis}

We used standard methodological procedures expected by Cochrane.

\section{Main results}

We did not identify any eligible studies.

\section{Authors' conclusions}

Since we did not identify any eligible studies, we are unable to draw any conclusions about the efficacy and toxicity of HDC with AHCT versus conventional chemotherapy in children, adolescents, and young adults with a first recurrence of Ewing sarcoma. Further highquality research is urgently needed.

\section{PLAIN LANGUAGE SUMMARY}

High-dose chemotherapy (HDC) and autologous haematopoietic cell transplantation (AHCT) for children, adolescents, and young adults with a first recurrence of Ewing sarcoma

\section{Review question}

We were looking for evidence on whether HDC plus AHCT improved event-free survival, overall survival, quality-adjusted survival, and progression-free survival better than conventional chemotherapy in children, adolescents, and young adults with their first recurrence of Ewing sarcoma. We were also looking for adverse effects that occurred because of these treatments.

\section{Background}

Ewing sarcoma is a tumour that occurs in the bone and soft tissue, especially in the long bones and pelvis, and mainly in children, adolescents and young adults. Since the introduction of chemotherapy following surgery, with or without radiation, the outcome of people with Ewing sarcoma has improved. However, even with improved chemotherapy, there are still too many people who eventually die of the disease, because it has progressed or come back. People with a first recurrence of Ewing sarcoma do not have a great prognosis: fewer than 3 out of 10 young people are still alive at 24 months, and fewer than 1 out of 10 are alive at 48 months. Improved therapy is essential for these people. High-dose chemotherapy (HDC), followed by autologous haematopoietic cell transplantation (AHCT; intravenous infusion of earlier collected stem cells to re-establish bone marrow), is successfully used for young people with a variety of tumours. Theoretically, this seems to be a good option to treat the small number of remaining cancer cells, and to improve the survival rate after the first recurrence of Ewing sarcoma.

\section{Key results}

We conducted an extensive search of the medical literature, including related conference proceedings, and registers for ongoing trials, but we did not find any relevant studies. Therefore, we are unable to draw any conclusions as to whether HDC with AHCT improves event-free survival, overall survival, quality-adjusted survival, or progression-free survival better than conventional chemotherapy, or if it causes any side effects, in children, adolescents, and young adults with their first recurrence of Ewing sarcoma. Our results show that further research is needed.

\section{How current is the evidence}

The evidence is current to January 2020. 


\section{SUMMARY OF FINDINGS}

\section{Summary of findings 1. High-dose chemotherapy with autologous haematopoietic cell transplantation versus conventional chemotherapy}

\section{High-dose chemotherapy with autologous haematopoietic cell transplantation versus conventional chemotherapy}

Patient or population: children, adolescents, and young adults with the first recurrence of Ewing sarcoma

Settings: (paediatric) oncology departments

Intervention: high-dose chemotherapy (HDC) with autologous haematopoietic cell transplantation (AHCT)

Comparison: conventional chemotherapy

\begin{tabular}{ll}
\hline Outcomes & Comments \\
\hline Event-free survival & No studies included \\
\hline Overall survival & No studies included \\
\hline Quality-adjusted survival & No studies included \\
\hline Toxicity & No studies included \\
\hline Progression-free survival & No studies included \\
\hline
\end{tabular}




\section{B A C K G R O U N D}

\section{Description of the condition}

Ewing sarcoma is a group of solid tumours consisting of small, blue, round cell neoplasms of neuroectodermal origin. Ewing sarcoma belongs to the Ewing family of tumours. The other types of tumours in the group are primitive neuroectodermal tumour (PNET), extraosseous Ewing sarcoma (EES), and Askin's tumour (Ewing sarcoma of the chest wall). These tumours are thought to arise from the same primordial stem cell. All of these tumours are defined by the presence of EWSR1-ETS gene re-arrangements. In $85 \%$ of cases, ETS transcription factor fuses with $F L I$, resulting in the EWS-FLI fusion protein. This $\mathrm{t}(11 ; 12)$ (q24;q12) chromosomal translocation can take place at different intron-exon sites, with more than 18 different translocations described (Delattre 1994; Potratz 2012). Ewing sarcoma is the second most common primary bone malignancy in children, accounting for $10 \%$ to $15 \%$ of all primary bone tumours, and approximately $3 \%$ of all malignancies in children (Cotterill 2000; Potratz 2012). Most often, Ewing sarcoma appears in bones; however, extraosseous manifestations do occur (Gurney 2006). The disease most often occurs in children, adolescents, and young adults, with an incidence rate of 4.5 per million a year, and a peak incidence of 11 per million at the age of 12 years (van den Berg 2008).

Much progress has been made in the treatment of Ewing sarcoma. With multi-modal treatment including multi-agent chemotherapy, surgery, and radiotherapy, young people with localised disease have survival rates of approximately $65 \%$ to $75 \%$. Several risk factors have been identified in young people with primary Ewing sarcoma: age above 14 years, tumour volume more than $200 \mathrm{~mL}$, more than one bone metastatic site; bone marrow metastases and additional lung metastases are correlated with a worse outcome (Ladenstein 2010). In young people with localised disease, those with tumours that respond poorly to chemotherapy, those with pelvic tumours, and those with high lactate dehydrogenase level at diagnosis have a worse prognosis (Bacci 2003; Cotterill 2000). Despite more intensive chemotherapy, $30 \%$ to $40 \%$ of young people with Ewing sarcoma will have recurrence of disease. For those with metastatic disease, overall survival is lower than $30 \%$ (Cotterill 2000; Ladenstein 2010; Potratz 2012; Rodriguez-Galindo 2008).

Relapse of Ewing sarcoma occurs at an average of 1.6 to 2.3 years after starting initial treatment (Bacci 1989; Rodrigues-Galindo 2007), although very late recurrences, more than 16 years after treatment of a primary tumour, have also been reported (Hanna 2008). In case of recurrence, about $70 \%$ of people present with metastatic disease. About $15 \%$ of people have a local recurrence and about $15 \%$ of people have combined local and metastatic disease (Bacci 1989; Barker 2005; Rodrigues-Galindo 2007; Stahl 2011). Isolated local recurrences occur less frequently, and are associated with a poor chemotherapeutic response (Lin 2007). Less than $30 \%$ of young people with recurrent Ewing sarcoma are alive at 24 months, and less than 10\% are alive at 48 months (Barker 2005; Cotterill 2000; Shankar 2003; Stahl 2011). Higher survival of young people with recurrences seems to be associated with the type of relapse and site of the metastases, treatment of relapse, response to second-line therapy, relapse more than two years after diagnosis, and no metastases at initial diagnosis (Bacci 2003; Barker 2005; Lin 2007; Shankar 2003).

\section{Description of the intervention}

The poor outcome for young people with recurrence of disease has led to the use of high-dose chemotherapy (HDC), followed by autologous haematopoietic cell transplantation (AHCT) in those who achieved a second complete remission after second-line treatment (Bacci 2003; Barker 2005; Burdach 2003; Gardner 2008; McTiernan 2006; Shankar 2003). Theoretically, this seems like a good treatment strategy to treat minimal residual disease, and to improve the survival rate after recurrence of disease.

\section{How the intervention might work}

After multi-modal treatment, including re-introduction of chemotherapy, the majority of young people will still harbour micro-metastatic deposits. The hypothesis is that HDC, or myeloablative conditioning regimens may overcome the resistance to standard multi-agent chemotherapy. Besides destroying the Ewing sarcoma cells, HDC also ablates the bone marrow reserve. Therefore, HDC is always followed by autologous haematopoietic cell transplantation.

\section{Why it is important to do this review}

The relative benefit of HDC followed by autologous haematopoietic cell rescue in recurrent disease is still controversial. Moreover, this treatment is associated with severe toxicity and adverse effects, including mucositis, metabolic problems, and long-lasting bone marrow aplasia, with the risk of life-threatening bleeding and infection (Burdach 2003; Gardner 2008). Some studies have reported improved disease-free survival (Al-Faris 2007; Barker 2005; McTiernan 2006), while other studies have shown no durable benefit over conventional therapies (Gardner 2008; Shankar 2003). This systematic review will contribute to the knowledge about the efficacy of HDC followed by AHCT in children, adolescents, and young adults with first recurrence of Ewing sarcoma.

\section{O B JECTIVES}

To assess the efficacy of high-dose chemotherapy with autologous haematopoietic cell transplantation versus conventional chemotherapy in improving event-free survival, overall survival, quality-adjusted survival, and progression-free survival in children, adolescents, and young adults with the first recurrence of Ewing sarcoma, and to determine the toxicity of the treatment.

\section{METHODS}

\section{Criteria for considering studies for this review}

\section{Types of studies}

Randomised controlled trials (RCTs) or (historical) controlled clinical trials (CCTs) comparing the effectiveness of highdose chemotherapy (HDC) and autologous haematopoietic cell transplantation (AHCT) with conventional chemotherapy for children, adolescents, and young adults with first recurrence of Ewing sarcoma.

To answer our objectives, the best study design, provided that the design and execution are correct, is an RCT. CCTs can also provide reliable information, keeping in mind their limitations, but other study designs were not eligible for this review due to the high risk of bias associated with other designs. 


\section{Types of participants}

Children, adolescents, and young adults (younger than 30 years on the date of diagnostic biopsy) with an earlier diagnosis of Ewing sarcoma confirmed by pathology, and with a first relapse of the disease. We excluded young people who received HDC with AHCT as the primary treatment, to make the groups more comparable. Previous HDC with AHCT is also associated with a higher risk of existing and worsening toxicity. We would have included studies that also included people who were not eligible for this review (e.g. people older than 30 years at tumour diagnosis), if separate data were available for the participants eligible for this review.

\section{Types of interventions}

HDC with AHCT as part of second-line treatment versus conventional chemotherapy. We defined HDC as chemotherapy that ablated the person's bone marrow reserves and created an absolute requirement for stem cell rescue. We defined conventional chemotherapy as chemotherapy given at a lower dose than HDC, which did not require stem cell rescue. We planned to include studies that added an immunotherapy to HDC with AHCT, however, we did not identify any.

\section{Types of outcome measures}

We did not use the outcomes listed here as criteria for including studies; instead, these were the outcomes of interest in studies identified for inclusion.

\section{Primary outcomes}

1. Event-free survival (as defined by the authors of the original study)

2. Overall survival (as defined by the authors of the original study)

3. Quality-adjusted survival (as defined by the authors of the original study)

4. Toxicity of the treatment (as defined by the authors of the original study)

\section{Secondary outcomes}

1. Progression-free survival (as defined by the authors of the original study)

\section{Search methods for identification of studies}

We used Cochrane Childhood Cancer's search strategy (Module CCG). We did not apply any language restrictions. The review authors ran all searches.

\section{Electronic searches}

We searched the following electronic databases:
1. Cochrane Central Register of Controlled Trials (CENTRAL; 2019, Issue 12) in the Cochrane Library (searched 1 January 2020);

2. MEDLINE PubMed (1966 to 1 January 2020);

3. Embase Ovid (1980 to 1 January 2020).

The search strategies for the different electronic databases (using a combination of controlled vocabulary and text words) are shown in Appendix 1; Appendix 2; and Appendix 3.

\section{Searching other resources}

We located information about trials not registered in CENTRAL, MEDLINE, and Embase, either published or unpublished, by searching the reference lists of relevant articles and review articles. We also screened the conference proceedings of the International Society for Paediatric Oncology (SIOP; 2009 to 2019), the American Society of Pediatric Hematology/Oncology (ASPHO; 2009 to 2019), the Connective Tissue Oncology Society (CTOS; 2009 to 2019), the American Society for Blood and Marrow Transplantation (ASBMT; 2009 to 2019), the European Society for Blood and Marrow Transplantation (EBMT; 2009 to 2019), and the European MusculoSkeletal Oncology Society (EMSOS; 2009 to 2019); we performed these searches electronically, if available, or by handsearching. We scanned ClinicalTrials.gov (www.clinicaltrials.gov; searched 1 January 2020), and the World Health Organization International Clinical Trials Registry Platform (WHO ICTRP; www.who.int/ictrp/ en/; searched 1 January 2020) for ongoing trials.

The search strategies for the different conference proceedings and trial registries (using a combination of controlled vocabulary and text words) are shown in Appendix 4 and Appendix 5.

\section{Data collection and analysis}

\section{Selection of studies}

After the search, two review authors independently identified studies that met the inclusion criteria for this review. We resolved discrepancies between review authors by discussion. If we could not reach consensus, we achieved final resolution using a thirdparty arbitrator. We obtained full reports of any study that seemed to meet the inclusion criteria on the grounds of the title or abstract, or both, for closer inspection. As we did not include any studies, we did not produce a 'Characteristics of included studies' table. We clearly stated detailed reasons for exclusion of any full-text study considered for the review in the 'Characteristics of excluded studies' table. We created a PRISMA flow diagram of the selection of studies in the review (Figure 1). Had there been multiple reports of the same study, we would have used the most recent report as the primary publication; we would have checked the other available reports for data not reported in the primary publication. 
Figure 1. Flowchart for study identification and selection

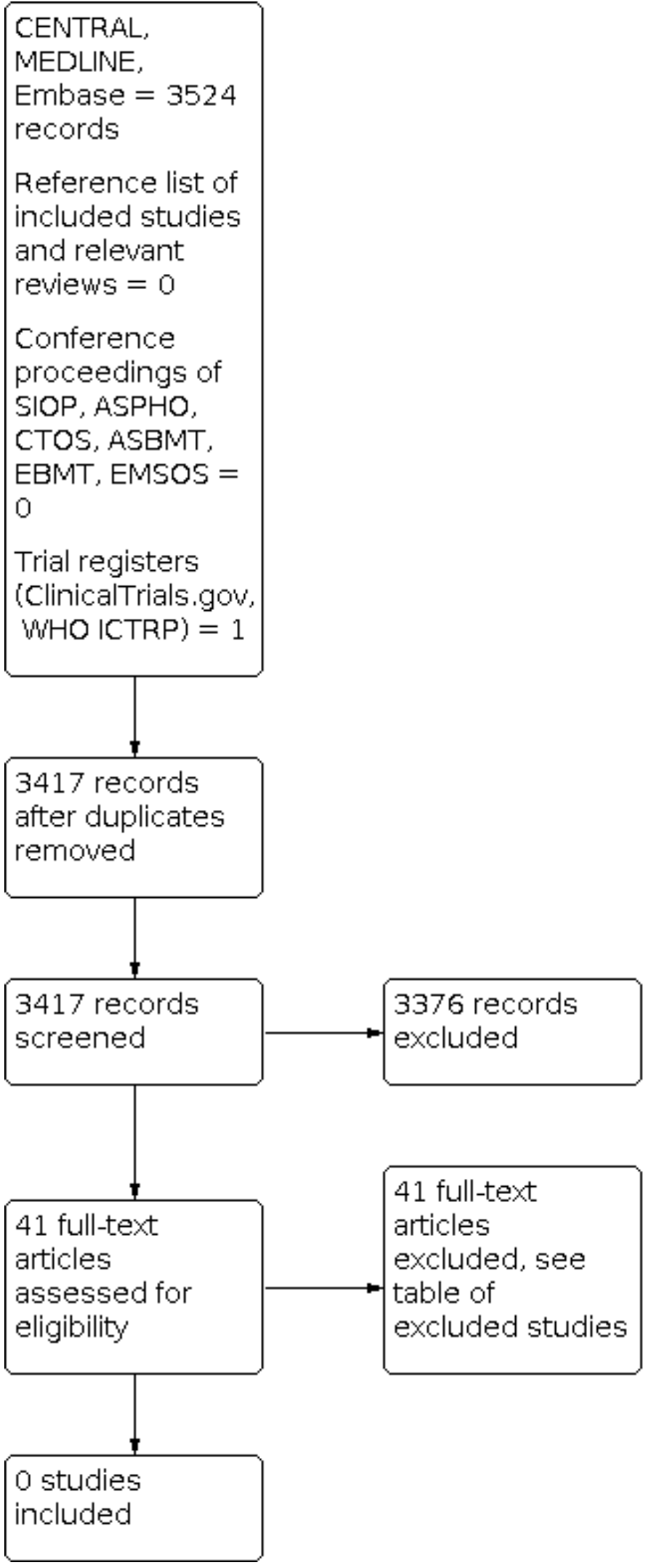




\section{Data extraction and management}

We did not identify any eligible studies. As a result, we did not extract or manage data. Should we find eligible studies during future updates of this review, we will follow the methods set out in our protocol, which are available in the Differences between protocol and review section.

\section{Assessment of risk of bias in included studies}

We did not identify any eligible studies, so risk of bias assessment was not applicable. Should we find eligible studies during future updates of this review, we will follow the methods set out in our protocol, which are available in the Differences between protocol and review section.

\section{Measures of treatment effect}

Measures of treatment effect were not an issue. Should we find eligible studies during future updates of this review, we will follow the methods set out in our protocol, which are available in the Differences between protocol and review section.

\section{Unit of analysis issues}

Unit of analysis issues were not an issue. Should we find eligible studies during future updates of this review, we will follow the methods set out in our protocol, which are available in the Differences between protocol and review section.

\section{Dealing with missing data}

Missing data was not an issue in this review, but for future updates we will follow the methods set out in our protocol, which are available in the Differences between protocol and review section.

\section{Assessment of heterogeneity}

Heterogeneity was not an issue. Should we find eligible studies during future updates of this review, we will follow the methods set out in our protocol, which are available in the Differences between protocol and review section.

\section{Assessment of reporting biases}

We did not identify any eligible studies. Therefore, we did not construct a funnel plot to assess reporting bias. Should we find eligible studies during future updates of this review, we will follow the methods set out in our protocol, which are available in the Differences between protocol and review section.

\section{Data synthesis}

As we did not identify any eligible studies, data synthesis was not an issue. Should we find eligible studies during future updates of this review, we will follow the methods set out in our protocol, which are available in the Differences between protocol and review section.

\section{Subgroup analysis and investigation of heterogeneity}

We had not planned any subgroup analyses.

\section{Sensitivity analysis}

Sensitivity analyses were not an issue. Should we find eligible studies during future updates of this review, we will follow the methods set out in our protocol, which are available in the Differences between protocol and review section.
Summary of findings and assessment of the certainty of the evidence

We prepared a summary of findings table, in which we presented the lack of evidence for event-free survival, overall survival, qualityadjusted survival, toxicity, and progression-free survival.

If we include studies during future updates, two review authors will independently assess the certainty of the evidence using the five GRADE considerations (i.e. study limitations, inconsistency, indirectness, imprecision, and publication bias).

\section{RE S U L T S}

\section{Description of studies}

\section{Results of the search}

We electronically searched CENTRAL, MEDLINE, and Embase on 1 January 2020, and identified 3524 records; see Figure 1. We identified one ongoing study through the search of ClinicalTrials.gov and WHO ICTRP, on 1 January 2020. Examining conference proceedings of aforementioned organisations did not identify any other studies. After removing duplicates, we screened the titles and abstracts of 3417 records. We excluded 3376 records for the following reasons: studies were duplicates, review articles, editorials or letters, or case reports, studies did not include participants with recurrent Ewing sarcoma. We evaluated the full text of 41 studies, all of which we excluded after full-text assessment because of an ineligible study design.

\section{Included studies}

We did not identify any studies that met our inclusion criteria.

\section{Excluded studies}

All excluded studies had an ineligible study design, i.e. not randomised controlled trials (RCT) or controlled clinical trials (CCT) comparing the effectiveness of high-dose chemotherapy (HDC) and autologous haematopoietic cell transplantation (AHCT) with conventional chemotherapy for children, adolescents, and young adults with the first recurrence of Ewing sarcoma). See Characteristics of excluded studies for more information.

\section{Risk of bias in included studies}

As we did not include any studies, there were no studies to assess for risk of bias.

\section{Effects of interventions}

See: Summary of findings 1 High-dose chemotherapy with autologous haematopoietic cell transplantation versus conventional chemotherapy

We did not identify any studies, therefore, the effects of HDC with AHCT compared with standard chemotherapy remain unclear for event-free survival, overall survival, quality-adjusted survival, toxicity, and progression-free survival in children, adolescents, and young adults with the first recurrence of Ewing sarcoma. See Summary of findings 1. 


\section{DISCUSSION}

\section{Summary of main results}

We did not identify any studies, therefore, the effects of highdose chemotherapy (HDC) and autologous haematopoietic cell transplantation (AHCT) compared with standard chemotherapy remain unclear for event-free survival, overall survival, qualityadjusted survival, toxicity, and progression-free survival in children, adolescents, and young adults with the first recurrence of Ewing sarcoma.

In this Cochrane Review we assessed the efficacy of HDC with AHCT versus conventional chemotherapy in improving event-free survival, overall survival, quality adjusted survival and progressionfree survival of children, adolescents and young adults with first recurrence of Ewing sarcoma and to determine the toxicity of the treatment. To answer this type of question the best study design, provided that the design and execution are correct, is an RCT. CCTs can also provide reliable information, keeping in mind their limitations, but other study designs were not eligible for inclusion in this review due to the high risk of bias associated with such designs. Unfortunately no eligible studies were identified.

\section{Overall completeness and applicability of evidence}

There is currently no evidence from randomised controlled or controlled clinical trials that assess the effects of HDC and AHCT with conventional chemotherapy for children, adolescents, and young adults with the first recurrence of Ewing sarcoma.

\section{Potential biases in the review process}

We attempted to ensure that we did not overlook any relevant evidence by performing a very extensive search for randomised controlled trials, and even included non-randomised controlled clinical studies. Therefore, it is very unlikely that we missed any eligible studies.

\section{Agreements and disagreements with other studies or reviews}

Our extensive literature search did not find any studies that were eligible for inclusion, which is in line with previously published reviews. One systematic review included all clinical studies with participants with a recurrence of Ewing sarcoma who were treated with HDC followed by AHCT. Tenetti 2018 included 24 studies, with total of 345 participants with a recurrence of Ewing sarcoma. None of the included studies were clinical trials that were either randomised or (historically) controlled. Therefore, a high level of any bias, especially selection of participants who were eligible for HDC with AHCT, might have influenced the observation by most studies that using HDC AHCT improved survival compared to conventional chemotherapy. The main conclusion was that prospective randomised controlled studies were needed to definitively define the role of HDC with AHCT in young people with a recurrence of Ewing sarcoma.

This is in line with the conclusions of this review, and a general Ewing sarcoma management review by international experts (Gaspar 2015). At the moment, we did not identify any ongoing trials.

\section{AUTHORS' CONCLUSIONS}

\section{Implications for practice}

Due to the current absence of evidence, we are unable to make any definitive conclusions concerning the role of highdose chemotherapy (HDC) and autologous haematopoietic cell transplantation (AHCT) in the treatment of a recurrence of Ewing sarcoma.

\section{Implications for research}

Randomised clinical trials, or well-executed controlled clinical trials, with sufficient numbers of people with recurrent Ewing sarcoma to obtain the power needed for reliable results, and an adequate duration of follow-up, are necessary to determine the efficacy of HDC with AHCT.

\section{ACK N OWLEDGEMENTS}

We would like to thank $\mathrm{Dr}$ Allen R Chen, MD, PhD of the Sidney Kimmel Comprehensive Cancer Center at Johns Hopkins, Baltimore, who peer reviewed this manuscript. We would also like to thank Prof. Heribert Juergens for his contribution to the development of the protocol. The Editorial base of Cochrane Childhood Cancer has been funded by KiKa, and is located in the Princess Máxima Center for Pediatric Oncology, Utrecht, the Netherlands. We would like to thank Edith Leclercq, former Information Specialist of Cochrane Childhood Cancer, for designing the search strategies. 


\section{R E F E R E N C E S}

\section{References to studies excluded from this review}

Al-Faris 2007 \{published data only\}10.1002/pbc.21140

Al-Faris N, Al Harbi T, Goia C, Pappo A, Doyle J, Gassas A. Does consolidation with autologous stem cell transplantation improve the outcome of children with metastatic or relapsed Ewing sarcoma? Pediatric Blood \& Cancer 2007;49(2):190-5. [DOI: 10.1002/pbc.21140]

\section{Avramova 2006 \{published data only\}}

Avramova B, Jordanova M, Michailov G, Konstantinov D, Christosova I, Bobev D. Myeloablative chemotherapy with autologous peripheral blood stem cell transplantation in patients with poor-prognosis solid tumors - Bulgarian experience. Journal of B.U.ON. 2006;11(4):433-8.

\section{Avramova 2011 \{published data only\}}

Avramova B, Jordanova M, Konstantinov D, Hristozova I, Shtarbanov I, Bobev D. Comparison of the treatment results after conventional and myeloablative chemotherapy in patients with poor prognosis Ewing's sarcoma family tumors - Single center experience. Journal of B.U.ON. 2011;16(3):551-6.

\section{Barker 2005 \{published data only\}}

Barker LM, Pendergrass TW, Sanders JE, Hawkins DS. Survival after recurrence of Ewing's sarcoma family of tumors. Journal of Clinical Oncology 2005;23(19):4354-62.

\section{Burdach 1991 \{published data only\}}

Burdach S, Peters C, Paulussen M, Nurnberger W, Wurm R, Wernet $\mathrm{P}$, et al. Improved relapse free survival in patients with poor prognosis Ewing's sarcoma after consolidation with hyperfractionated total body irradiation and fractionated high dose melphalan followed by high dose etoposide and hematopoietic rescue. Bone Marrow Transplantation 1991;7(Suppl 2):95.

\section{Burdach 1993 \{published data only\}}

Burdach S, Jurgens H, Peters C, Nurnberger W, Mauz-Korholz C, Korholz D, et al. Myeloablative radiochemotherapy and hematopoietic stem-cell rescue in poor-prognosis Ewing's sarcoma. Journal of Clinical Oncology 1993;11(8):1482-8.

\section{Clara 2012 \{published data only\}10.1038/bmt.2012.37}

Clara A, Moita F, Ferreira I, Teixeira G, Miranda N, Leal Da Costa F, et al. Autologous stem cell transplantation for high-risk Ewing's sarcoma: a single-centre review. Bone Marrow Transplantation 2012;47:S425. [DOI: 10.1038/bmt.2012.37]

\section{Cristofani 2013 \{published data only\}10.1111/petr.12037}

Cristofani LM, Fernandes JF, Almeida MTA, Cornacchioni ALB, Azambuja AP, Gomes A, et al. Megachemotherapy with hematopoietic stem cell rescue for the treatment of children with advanced solid tumors. Pediatric Transplantation 2013;17(2):192. [DOI: 10.1111/petr.12037]

\section{Diaz 2010 \{published data only\}10.3109/08880011003639994} Diaz MA, Lassaletta A, Perez A, Sevilla J, Madero L, GonzalezVicent M. High-dose busulfan and melphalan as conditioning regimen for autologous peripheral blood progenitor cell transplantation in high-risk Ewing sarcoma patients: a longterm follow-up single-center study. Pediatric Hematology and Oncology 2010;27(4):272-82. [DOI: 10.3109/08880011003639994]

Dirksen 2019 \{published data only\}10.1200/JCO.19.00915

Dirksen U, Brennan B, Le Deley MC, Cozic N, van den Berg H, Bhadri V, et al, Euro-EWING 99 and Ewing 2008 Investigators. High-dose chemotherapy compared with standard chemotherapy and lung radiation in Ewing sarcoma with pulmonary metastases: results of the European Ewing Tumour Working Initiative of National Groups, 99 Trial and Ewing 2008. Journal of Clinical Oncology 2019;37(34):3192-202. [PMID: 10.1200/JCO.19.00915]

Drabko 2005 \{published data only\}10.1111/ j.1399-3046.2005.00359.x

Drabko K, Zawitkowska-Klaczynska J, Wojcik B, Choma M, Zaucha-Prazmo A, Kowalczyk J, et al. Megachemotherapy followed by autologous stem cell transplantation in children with Ewing's sarcoma. Pediatric Transplantation 2005;9(5):618-21. [DOI: 10.1111/j.1399-3046.2005.00359.x]

Drabko 2006 \{published data only\}

Drabko K, Choma M, Zaucha-Prazmo A, Wojcik B, Gorczynska E, Kalwak K, et al. Megachemotherapy and autologous hematopoietic stem cell transplantation in children with solid tumours excluding neuroblastoma - experience of Polish paediatric centres. Medycyna wieku rozwojowego 2006;10(3 Pt 1):785-92

\section{Drabko 2009 \{published data only\}10.1002/pbc.22234}

Drabko K, Zaucha-Prazmo A, Choma M, Wojcik B, Dyla A, Kalwak K, et al. Eficacy of megachemotherapy and autologous stem cell transplantation in patients with Ewing sarcoma high risk group. PN. 022. Pediatric Blood \& Cancer 2009;53(5):842-3. [DOI: $10.1002 / p b c .22234]$

\section{Elhasid 2012 \{published data only\}10.1038/bmt.2012.37}

Elhasid R, Bitan M, Cohen-Neuman N, Porat I, Furer R, Levin D, et al. Autologous stem cell transplantation in Ewing's sarcoma: the experience of Rambam Medical Centre and Tel Aviv Medical Centre. Bone Marrow Transplantation 2012;47:S425-6. [DOI: 10.1038/bmt.2012.37]

\section{Escobar 2010 \{published data only\}10.1002/pbc.22779}

Escobar NF, Saa G, Trentadue J, Drelichman G, Jaimovich G, Guiterrez M, et al. Autologous hematopoietic stem cell transplantation for solid tumors. One group experience. Pediatric Blood \& Cancer 2010;55(5):930-1. [DOI: 10.1002/ pbc.22779]

\section{Ferrari 2015 \{published data only\}10.1002/pbc.25388}

Ferrari S, Luksch R, Hall KS, Fagioli F, Prete A, Tamburini A, et al. Post-relapse survival in patients with Ewing sarcoma. Pediatric Blood \& Cancer 2015;62(6):994-9. [DOI: 10.1002/pbc.25388] 
Fraser 2006 \{published data only\}10.1038/sj.bmt.1705224

Fraser CJ, Weigel BJ, Perentesis JP, Dusenbery KE, DeFor TE, Baker KS, et al. Autologous stem cell transplantation for highrisk Ewing's sarcoma and other pediatric solid tumors. Bone Marrow Transplantation 2006;37(2):175-81. [DOI: 10.1038/ sj.bmt.1705224]

\section{Frohlich 1999 \{published data only\}10.1055/s-2008-1043801}

Frohlich B, Ahrens S, Burdach S, Klingebiel T, Ladenstein R, Paulussen $\mathrm{M}$, et al. High-dosage chemotherapy in primary metastasized and relapsed Ewing's sarcoma. (EI) CESS. Klinische Padiatrie 1999;211(4):284-90. [DOI: 10.1055/s-2008-1043801]

\section{Gardner 2008 \{published data only\}10.1038/bmt.2008.2}

Gardner SL, Carreras J, Boudreau C, Camitta BM, Adams RH, Chen AR, et al. Myeloablative therapy with autologous stem cell rescue for patients with Ewing sarcoma. Bone Marrow Transplantation 2008;41(10):867-72. [DOI: 10.1038/bmt.2008.2]

\section{Hazar 2015 \{published data only\}10.1002/pbc.25715}

Hazar V, Karakukcu M, Kupesiz A, Kesik V, Kocak U, Eker N, et al. Hematopoietic stem cell transplantation in relapsed or refractory extracranial primitive neuroectodermal tumor of children and adolescents: a multicenter survey study. Pediatric Blood \& Cancer 2015;62:S266. [DOI: 10.1002/pbc.25715]

Jodele 2010 \{published data only\}10.1016/j.bbmt.2009.12.108 Jodele S, Davies SM, Wagner LM, Mehta PA, Bleesing JJ, Filipovich $\mathrm{AH}$, et al. Outcomes with high dose chemotherapy and Autologous Stem Cell Transplantation (ASCT) in comparison to conventional chemotherapy in pediatric patients with high risk Ewing's family tumors. Biology of Blood and Marrow Transplantation 2010;16(2 Suppl 2):S186. [DOI: 10.1016/ j.bbmt.2009.12.108]

\section{Kabickova 2003 \{published data only\}}

Kabickova E. High-dose chemotherapy with autologous hematopoietic stem cell transplantation for pediatric solid tumors. Klinicka Onkologie 2003;16(Suppl 1):119-21.

\section{Kasper 2004 \{published data only\}10.1038/sj.bmt.1704520}

Kasper B, Lehnert T, Bernd L, Mechtersheimer G, Goldschmidt H, Ho AD, et al. High-dose chemotherapy with autologous peripheral blood stem cell transplantation for bone and soft-tissue sarcomas. Bone Marrow Transplantation 2004;34(1):37-41. [DOI: 10.1038/sj.bmt.1704520]

\section{Kasper 2007 \{published data only\}10.1159/000120629}

Kasper B, Dietrich S, Mechtersheimer G, Ho AD, Egerer G. Large institutional experience with dose-intensive chemotherapy and stem cell support in the management of sarcoma patients. Oncology 2007;73(1-2):58-64. [DOI: 10.1159/000120629]

\section{Ladenstein 1995 \{published data only\}}

Ladenstein R, Gadner H, Hartmann O, Pico J, Biron P, Thierry P. European experience with megatherapy and ABMT in poor prognosis solid tumors (Ewing's sarcoma, germ cell tumors and brain tumors). Wiener Medizinische Wochenschrift 1995;145(2-3):55-7.

\section{Ladenstein 2014 \{published data only\}10.1002/pbc.25314}

Ladenstein R, Valteau-Couanet D, Glogova E, Juergens $H$, Burdach S, Michon J, et al. The role of megatherapy (MGT) and stem cell transplantation (SCT) in high risk Ewing tumors (ET): more than 30 years of EBMT activity. Pediatric Blood \& Cancer 2014;61:S176. [DOI: 10.1002/pbc.25314]

Malis $\mathbf{2 0 0 0}$ \{published data only\}

Malis J, Kavan P, Kabickova E, Jerabkova V, Valkova J, Stejskalova S. Treatment of high risk Ewing's sarcoma in children and adolescents. Experience of the Department of Pediatric Oncology, Faculty Hospital Motol. Cesko-Slovenska Pediatrie 2000;55(5):300-4.

\section{MarcusJr 1988 \{published data only\}}

Marcus RB Jr, Graham-Pole JR, Springfield DS, Fort JA, Gross S, Mendenhall NP, et al. High-risk Ewing's sarcoma: endintensification using autologous bone marrow transplantation. International Journal of Radiation Oncology Biology Physics 1988;15(1):53-9.

\section{McTiernan 2006 \{published data only\}10.1093/annonc/mdl108} McTiernan A, Driver D, Michelagnoli MP, Kilby AM, Whelan JS. High dose chemotherapy with bone marrow or peripheral stem cell rescue is an effective treatment option for patients with relapsed or progressive Ewing's sarcoma family of tumours. Annals of Oncology 2006;17(8):1301-5. [DOI: 10.1093/annonc/ mdl108]

\section{Palmerini 2009 \{published data only\}}

* Palmerini E, Brach Del Prever A, Fagioli F, Luksch R, Prete A, Tamburini A, et al. High-dose chemotherapy with autologous stem cell transplantation for relapsed Ewing's sarcoma. Journal of Clinical Oncology 2009;27(15_Suppl):10545.

\section{Pape 1999 \{published data only\}10.1007/s000660050058}

Pape H, Laws HJ, Burdach S, Van Kaik B, Glag M, Gripp S, et al. Radiotherapy and high-dose chemotherapy in advanced Ewing's tumors. Strahlentherapie und Onkologie 1999;175(10):484-7. [DOI: 10.1007/s000660050058]

Pawlowska 2012 \{published data only\}10.1016/

j.bbmt.2011.12.135

Pawlowska AB, Wolfson JA, Cheng J, Sorrell A, Sato J, Anderson C, et al. High dose chemotherapy (HDT) with busulfan, melphalan and topotecan followed by autologous hematopoietic stem cell transplantation (ASCT) in pediatric patients (PTS) with high risk solid tumors. Biology of Blood and Marrow Transplantation 2012;2:S249-50. [DOI: 10.1016/ j.bbmt.2011.12.135]

\section{Perentesis 1999 \{published data only\}}

Perentesis JP, Katsanis E, DeFor TE, Neglia JP, Ramsay NKC. Autologous stem cell transplantation for high-risk pediatric solid tumors. Bone Marrow Transplantation 1999;24(6):609-15.

\section{Petrovitch 2009 \{published data only\}}

Petrovitch S, Zhavrid E, Aleinikova O, Kiselev L, Strongin YU, Baranau Y, et al. Experience in high-dose chemotherapy with peripheral stem cell rescue and biotherapy for young adults 
with high-risk Ewing/PNET sarcoma. European Journal of Cancer 2009;7(2-3):598.

Pimenov 2009 \{published data only\}10.3205/ctt-2009-No5abstract03

Pimenov RI, Dolgopolov IS, Boyarshinov VK, Subbotina NS, Visochin IV, Siegiel S, et al. Treatment of patients with highrisk axial and pelvic Ewing's sarcoma (ES). A single-institution experience. Cellular Therapy and Transplantation 2009;2(5):94. [DOI: 10.3205/ctt-2009-No5-abstract03]

\section{Pimenov 2013 \{published data only\}10.1002/pbc.24509}

Pimenov R, Dolgopolov I, Subbotina N, Boyarshinov V, Mentkevich G. Treatment of patients with high-risk axial and pelvic Ewing's sarcoma (ES). A single-institution experience. Pediatric Blood \& Cancer 2013;60:S103. [DOI: 10.1002/ pbc.24509]

\section{Rasper 2013 \{published data only\}10.1002/pbc.25042}

Rasper M, Jabar S, Ranft A, Jurgens H, Amler S, Dirksen U. The value of high-dose chemotherapy in patients with first relapsed Ewing sarcoma. Pediatric Blood \& Cancer 2014;61(8):1382-6. [DOI: 10.1002/pbc.25042]

\section{Seo 2013 \{published data only\}10.3345/kjp.2013.56.9.401}

Seo J, Kim DH, Lim JS, Koh JS, Yoo JY, Kong CB, et al. Highdose chemotherapy and autologous peripheral blood stem cell transplantation in the treatment of children and adolescents with Ewing sarcoma family of tumors. Korean Journal of Pediatrics 2013;56(9):401-6. [DOI: 10.3345/kjp.2013.56.9.401]

\section{Stradella 2011 \{published data only\}}

Stradella A, Lopez-Pousa A, Quintana MJ, Murata P, Ortin M, Gallego O, et al. High-dose chemotherapy plus autologous stem cell transplantation (HDCT/SCT) in patients with sarcoma: a single institution experience. Journal of Clinical Oncology 2011;29(15 Suppl):10042.

Suzuki 2015 \{published data only\}10.1093/annonc/mdv472.156 Suzuki R, Takahashi Y, Inoue M, Kanamori H, Hashii Y, Sakamaki H, et al. Thiotepa for autologous hematopoietic stem cell transplantation for solid tumors. Annals of Oncology 2015;26:vii140-1. [DOI: 10.1093/annonc/mdv472.156]

Whelan 2018 \{published data only\}10.1200/JCO.2018.78.2516 Whelan J, Le Deley MC, Dirksen U, Le Teuff G, Brennan B, Gaspar N, et al, Euro-EWING 99 and Ewing 2008 Investigators. High-dose chemotherapy and blood autologous stem-cell rescue compared with standard chemotherapy in localized high-risk Ewing sarcoma: Results of Euro-EWING 99 and Ewing-2008. Journal of Clinical Oncology 2018;36(31):3110-9. [DOI: 10.1200/JCO.2018.78.2516]

\section{Additional references}

\section{Bacci 1989}

Bacci G, Toni A, Avella M, Manfrini M, Sudanese A, Ciaroni D, et al. Long-term results in 144 localized Ewing's sarcoma patients treated with combined therapy. Cancer 1989;63(8):1477-86.

\section{Bacci 2003}

Bacci G, Ferrari S, Longhi A, Donati D, De Paolis M, Forni C, et al. Therapy and survival after recurrence of Ewing's tumors: the Rizzoli experience in 195 patients treated with adjuvant and neoadjuvant chemotherapy from 1979 to 1997. Annals of Oncology 2003;14(11):1654-9.

\section{Burdach 2003}

Burdach S, Meyer-Bahlburg A, Laws HJ, Haase R, van Kaik B, Metzner B, et al. High-dose therapy for patients with primary multifocal and early relapsed Ewing's tumors: results of two consecutive regimens assessing the role of total-body irradiation. Journal of Clinical Oncology 2003;21(16):3072-8.

\section{Cotterill 2000}

Cotterill SJ, Ahrens S, Paulussen M, Jürgens HF, Voûte PA. Prognostic factors in Ewing's tumor of bone: analysis of 975 patients from the European Intergroup Cooperative Ewing's Sarcoma Study Group. Journal of Clinical Oncology 2000;18(17):3108-14.

\section{Delattre 1994}

Delattre O, Zucman J, Melot T. The Ewing family of tumors a subgroup of small-round-cell tumors defined by specific chimeric transcripts. New England Journal of Medicine 1994;331:294-9.

\section{Gaspar 2015}

Gaspar N, Hawkins DS, Dirksen U, Lewis IJ, Ferrari S, Le Deley $\mathrm{M}$, et al. Ewing sarcoma: current management and future approaches through collaboration. Journal of Clinical Oncology 2015;33(27):3036-46. [DOI: 10.1200/JCO.2014.59.5256]

\section{GRADEpro GDT [Computer program]}

McMaster University (developed by Evidence Prime) GRADEpro GDT. Hamilton (ON): McMaster University (developed by Evidence Prime). Available at gradepro.org.

\section{Gurney 2006}

Gurney J, Swensen A, Bulterys M. Malignant Bone Tumors. Vol. In: Cancer Incidence and Survival Among Children and Adolescents: United States SEER Program, 1975-1995. Bethesda: SEER Pediatric Monograph; National Cancer Institute, 1999.

\section{Hanna 2008}

Hanna SA, David LA, Gikas PD, Tindall AJ, Cannon SR, Briggs TW. Very late local recurrence of Ewing's sarcoma - can you ever say 'cured'? A report of two cases and literature review. Annals of the Royal College of Surgeons of England 2008;90(7):W12-5.

\section{Higgins 2011}

Higgins JP, Green S, editor(s). Cochrane Handbook for Systematic Reviews of Interventions Version 5.1.0 (updated March 2011). The Cochrane Collaboration, 2011. Available from training.cochrane.org/handbook/archive/v5.1/.

\section{Ladenstein 2010}

Ladenstein R, Pötschger U, Le Deley MC, Whelan J, Paulussen M, Oberlin O, et al. Primary disseminated multifocal Ewing 
sarcoma: results of the Euro-EWING 99 trial. Journal of Clinical Oncology 2010;28(20):3284-91.

\section{Lin 2007}

Lin PP, Jaffe N, Herzog CE, Costelloe CM, Deavers MT, Kelly JS, et al. Chemotherapy response is an important predictor of local recurrence in Ewing sarcoma. Cancer 2007;109(3):603-11.

\section{Module CCG}

Kremer LCM, van Dalen EC, Moher D, Caron HN. Cochrane Childhood Cancer Group. About The Cochrane Collaboration (Cochrane Review Groups (CRGs)) 2010;(12).

\section{Potratz 2012}

Potratz J, Dirksen U, Jürgens H, Craft A. Ewing sarcoma: clinical state-of-the-art. Pediatric Hematology and Oncology 2012;29(1):1-11.

\section{Review Manager 2020 [Computer program]}

The Cochrane Collaboration Review Manager 5 (RevMan 5). Version 5.4. The Cochrane Collaboration, 2020.

\section{Rodrigues-Galindo 2007}

Rodríguez-Galindo C, Liu T, Krasin MJ, Wu J, Billups CA, Daw NC, et al. Analysis of prognostic factors in Ewing sarcoma family of tumors: review of St. Jude Children's Research Hospital studies. Cancer 2007;110(2):375-84.

\section{Rodriguez-Galindo 2008}

Rodríguez-Galindo C, Navid F, Liu T, Billups CA, Rao BN, Krasin MJ, et al. Prognostic factors for local and distant control in Ewing sarcoma family of tumors. Annals of Oncology 2008;19(4):814-20.

\section{Shankar 2003}

Shankar AG, Ashley S, Craft AW, Pinkerton CR. Outcome after relapse in an unselected cohort of children and adolescents

\section{CHARACTERISTICS OF STUDIES}

Characteristics of excluded studies [ordered by study ID] with Ewing sarcoma. Medical and Pediatric Oncology 2003;40(3):141-7.

\section{Stahl 2011}

Stahl M, Ranft A, Paulussen M, Bölling T, Vieth V, Bielack S, et al. Risk of recurrence and survival after relapse in patients with Ewing sarcoma. Pediatric Blood and Cancer 2011;57(4):549-53.

\section{Tenetti 2018}

Tenneti P, Zahid U, Iftikhar A, Yun S, Sohail A, Warraich Z, et al. Role of high-dose chemotherapy and autologous hematopoietic cell transplantation for children and young adults with relapsed Ewing's sarcoma: a systematic review. Sarcoma 2018 June 3;2018:Article ID. 2640674. [DOI: 10.1155/2018/2640674]

\section{van den Berg 2008}

van den Berg H, Kroon HM, Slaar A, Hogendoorn P. Incidence of biopsy-proven bone tumors in children: a report based on the Dutch pathology registration "PALGA". Journal of Pediatric Orthopaedics 2008;28(1):29-35.

\section{References to other published versions of this review \\ Haveman 2014}

Haveman LM, Breunis WB, van Dalen EC, Kremer LCM, Jürgens H, Dirksen U, et al. High-dose chemotherapy followed by autologous haematopoietic cell transplantation for children, adolescents and young adults with first recurrence of Ewing sarcoma. Cochrane Database of Systematic Reviews 2014, Issue 12. Art. No: CD011406. [DOI: 10.1002/14651858.CD011406]

* Indicates the major publication for the study

\begin{tabular}{ll}
\hline Study & Reason for exclusion \\
\hline Al-Faris 2007 & Ineligible design \\
\hline Avramova 2006 & Ineligible design \\
\hline Avramova 2011 & Ineligible design \\
\hline Barker 2005 & Ineligible design \\
\hline Burdach 1991 & Ineligible design \\
\hline Burdach 1993 & Ineligible design \\
\hline Clara 2012 & Ineligible design \\
\hline
\end{tabular}




\begin{tabular}{|c|c|}
\hline Study & Reason for exclusion \\
\hline Cristofani 2013 & Ineligible design \\
\hline Diaz 2010 & Ineligible design \\
\hline Dirksen 2019 & Ineligible design \\
\hline Drabko 2005 & Ineligible design \\
\hline Drabko 2006 & Ineligible design \\
\hline Drabko 2009 & Ineligible design \\
\hline Elhasid 2012 & Ineligible design \\
\hline Escobar 2010 & Ineligible design \\
\hline Ferrari 2015 & Ineligible design \\
\hline Fraser 2006 & Ineligible design \\
\hline Frohlich 1999 & Ineligible design \\
\hline Gardner 2008 & Ineligible design \\
\hline Hazar 2015 & Ineligible design \\
\hline Jodele 2010 & Ineligible design \\
\hline Kabickova 2003 & Ineligible design \\
\hline Kasper 2004 & Ineligible design \\
\hline Kasper 2007 & Ineligible design \\
\hline Ladenstein 1995 & Ineligible design \\
\hline Ladenstein 2014 & Ineligible design \\
\hline Malis 2000 & Ineligible design \\
\hline MarcusJr 1988 & Ineligible design \\
\hline McTiernan 2006 & Ineligible design \\
\hline Palmerini 2009 & Data published in Ferrari 2015. \\
\hline Pape 1999 & Ineligible design \\
\hline Pawlowska 2012 & Ineligible design \\
\hline Perentesis 1999 & Ineligible design \\
\hline Petrovitch 2009 & Ineligible design \\
\hline Pimenov 2009 & Ineligible design \\
\hline
\end{tabular}

High-dose chemotherapy followed by autologous haematopoietic cell transplantation for children, adolescents, and young adults with 


\begin{tabular}{ll}
\hline Study & Reason for exclusion \\
\hline Pimenov 2013 & Ineligible design \\
\hline Rasper 2013 & Ineligible design \\
\hline Seo 2013 & Ineligible design \\
\hline Stradella 2011 & Ineligible design \\
\hline Suzuki 2015 & Ineligible design \\
\hline Whelan 2018 & Ineligible design \\
\hline
\end{tabular}

\section{APPENDICES}

\section{Appendix 1. Search strategy for CENTRAL}

1. For Ewing sarcoma, we used the following text words:

ewing OR ewings OR ewing* OR ewing sarcoma OR peripheral neuroectodermal tumor OR peripheral neuroectodermal tumour OR peripheral neuroectodermal tumors OR peripheral neuroectodermal tumours OR primitive neuroectodermal tumor OR primitive neuroectodermal tumour OR primitive neuroectodermal tumors OR primitive neuroectodermal tumours OR Primitive Neuroepithelial Tumor OR Primitive Neuroepithelial Tumors OR Primitive Neuroepithelial Tumour OR Primitive Neuroepithelial Tumours OR Primitive Neuroepithelial Neoplasm OR Primitive Neuroepithelial Neoplasms OR PNET OR PNETs OR neuroepithelioma OR neuroepitheliomas OR (askin AND (tumor OR tumors OR tumour OR tumours))

2. For autologous hematopoietic cell transplantation, we used the following text words:

bone marrow transplantation or bone marrow grafting or bone marrow cell transplantation or stem cell transplantation or stem cell transplantations or hematopoietic stem cell transplantation or haematopoietic stem cell transplantation or hematopoietic cell transplantation or haematopoietic cell transplantation or HSCT or HCT or peripheral blood stem cell transplantation or peripheral stem cell transplantation or autograft or autografts or transplantation, autologous or autotransplant or autotransplants or ABMT or PBSCT or transplant* or homolog* or autolog* or BMT or myeloablative therapy or myeloablative agonist or myeloablative agonists or myeloablativ ${ }^{\star}$ or mega therapy or stem cell rescue or bone marrow rescue or high-dose therapy or high dose therapy or homograft or homografts or homologous transplantation or homologous transplantations or transplantations, homologous or transplantation, homologous or transplantations

Final search 1 and 2

The search was performed in title, abstract or keywords

$\left({ }^{*}=\right.$ zero or more characters $)$

\section{Appendix 2. Search strategy for MEDLINE PubMed}

1. For Ewing sarcoma, we used the following MeSH headings and text words:

ewing OR ewings OR ewing* OR ewing sarcoma OR ewing's sarcoma OR "peripheral neuroectodermal tumor" OR "peripheral neuroectodermal tumour" OR "peripheral neuroectodermal tumors" OR "peripheral neuroectodermal tumours" OR "primitive neuroectodermal tumor" OR "primitive neuroectodermal tumour" OR "primitive neuroectodermal tumors" OR "primitive neuroectodermal tumours" OR "Primitive Neuroepithelial Tumor" OR "Primitive Neuroepithelial Tumors" OR "Primitive Neuroepithelial Tumour" OR "Primitive Neuroepithelial Tumours" OR "Primitive Neuroepithelial Neoplasm" OR "Primitive Neuroepithelial Neoplasms" OR "PNET" OR "PNETs" OR neuroepithelioma[tw] OR neuroepitheliomas[tw] OR neuroectodermal tumors, primitive, peripheral[Mesh:NoExp] OR neuroectodermal tumors, primitive[Mesh:NoExp] OR (askin AND (tumor OR tumors OR tumour OR tumours))

2. For autologous hematopoietic cell transplantation, we used the following MeSH headings and text words:

bone marrow transplantation OR bone marrow grafting OR bone marrow cell transplantation OR stem cell transplantation OR stem cell transplantations OR hematopoietic stem cell transplantation OR haematopoietic stem cell transplantation OR hematopoietic cell 
transplantation OR haematopoietic cell transplantation OR HSCT OR HCT OR peripheral blood stem cell transplantation OR peripheral stem cell transplantation OR autograft OR autografts OR transplantation, autologous OR autotransplant OR autotransplants OR ABMT OR PBSCT OR transplant* OR homolog* OR autolog* OR BMT OR "myeloablative therapy" OR myeloablative agonist OR myeloablative agonists OR myeloablativ* OR "mega therapy" OR stem cell rescue OR bone marrow rescue OR "high-dose therapy" OR "high dose therapy" OR homograft OR homografts OR homologous transplantation OR homologous transplantations OR transplantations, homologous OR transplantation, homologous OR transplantations

Final search 1 AND 2

$\left({ }^{*}=\right.$ zero or more characters; $\mathrm{tw}=$ text word $)$

\section{Appendix 3. Search strategy for Embase Ovid}

1. ForEwing sarcoma, we used the following Emtree terms and text words:

1. (ewing or ewings or ewing\$).ti,ab.

2. exp Ewing sarcoma/

3. (ewing sarcoma or ewing's sarcoma).mp.

4. (PNET or PNETs).mp.

5. (peripheral neuroectodermal tumor or peripheral neuroectodermal tumors or peripheral neuroectodermal tumour or peripheral neuroectodermal tumours).mp.

6. (primitive neuroectodermal tumor or primitive neuroectodermal tumors or primitive neuroectodermal tumour or primitive neuroectodermal tumours).mp.

7. (primitive neuroepithelial tumor or primitive neuroepithelial tumors or primitive neuroepithelial tumour or primitive neuroepithelial tumours).mp.

8. neuroectoderm tumor/ or neuroepithelioma/ or (neuroepithelioma or neuroepitheliomas).mp.

9. (Primitive Neuroepithelial Neoplasm or Primitive Neuroepithelial Neoplasms).mp.

10. (askin and (tumor or tumors or tumour or tumours)).mp.

11. or/1-10

2. For autologous hematopoietic cell transplantation, we used the following Emtree terms and text words:

1. (bone marrow transplantation or bone marrow grafting).mp.

2. (bone marrow cell transplantation or stem cell transplantation or stem cell transplantations).mp.

3. (hematopoietic stem cell transplantation or haematopoietic stem cell transplantation or HSCT or HCT or peripheral blood stem cell transplantation).mp.

4. peripheral stem cell transplantation.mp.

5. (autograft or autografts).mp.

6. autograft/

7. (autologous transplantation or autotransplant or autotransplants).mp.

8. (BMT or ABMT or PBSCT).mp.

9. transplant\$.mp.

10. (autolog\$ or homolog\$).mp.

11. myeloablative therapy.mp.

12. (myeloablative agonist or myeloablative agonists).mp.

13. myeloablativ\$.mp.

14. mega therapy.mp.

15. (high-dose therapy or high dose therapy).mp.

16. (stem cell rescue or bone marrow rescue).mp.

17. (homograft or homografts).mp.

18. (homologous transplantation or homologous transplantations).mp.

19. transplantations.mp.

20. or/1-19

Final search 1 and 2

( $\mathrm{mp}$ = title, abstract, subject headings, heading word, drug trade name, original title, device manufacturer, drug manufacturer name; ti,ab = title, abstract; / = Emtree term; $\$$ = zero or more characters)

\section{Appendix 4. Search strategy for conference proceedings}

We scanned the conference proceedings of the International Society for Paediatric Oncology (SIOP; 2009 to 2019), the American Society of Pediatric Hematology/Oncology (ASPHO; 2009 to 2019), the Connective Tissue Oncology Society (CTOS; 2009 to 2019), the American Society for Blood and Marrow Transplantation (ASBMT; 2009 to 2019), the European Society for Blood and Marrow Transplantation (EBMT; 
2009 to 2019) and the European Musculo-Skeletal Oncology Society (EMSOS; 2009 to 2019). Conference proceedings were available in pdf. All pdf files were assessed using the term 'Ewing' and scanned for applicability for this review.

\section{Appendix 5. Search strategy for ongoing trials}

For ClinicalTrials.gov, we used the following search strategy:

We used the advanced search option for studies first received or first posted to 01 January 2020. The search terms used were: Ewing OR Ewing sarcoma. We applied the following search filters: recruitment [not yet recruiting; recruiting; enrolling by invitation; active, not recruiting; suspended]; Age [child; adult]; study type [interventional (clinical trial).

For the World Health Organization International Clinical Trials Registry Platform (WHO ICTRP), we used the

following search strategy:

1. Ewing OR Ewing sarcoma in the title field

2. Ewing OR Ewing sarcoma in the conditions field

3. Busulfan OR Treosulfan OR Melphalan OR High dose OR Autologous OR stem cell

We used the advanced search option with recruitment status 'recruiting' and date of registration to 1 January 2020.

\section{H I S T O R Y}

Protocol first published: Issue 12, 2014

\section{CONTRIBUTIONSOF AUTHORS}

LH: designed and drafted the protocol, performed the study selection, created tables, drafted the manuscript

RE: performed the study selection, created tables, drafted the manuscript

WB: designed and drafted the protocol, revised the manuscript

ED: designed and drafted the protocol, third party arbitration for study selection, provided methodological support, and drafted the manuscript

LK, UD, HvdB: reviewed the draft protocol, gave general advice on the review, and revised the manuscript

JM: revised the protocol and manuscript, supervised the review process, third party arbitrator for study selection.

All authors approved the final version.

\section{DECLARATIONSOF INTEREST}

None known

\section{SOURCES OF SUPPORT}

\section{Internal sources}

- No sources of support provided

\section{External sources}

- Tom Voûte Fund, Netherlands

- Stichting Kinderen Kankervrij; Children Cancer Free Foundation (KiKa), Netherlands

- SKOCA Foundation (Pediatric Oncology Center Amsterdam), Netherlands

\section{DIFFERENCES BETWEEN PROTOCOL AND REVIEW}

As we did not include any studies in this review, most of the methodology described in the protocol for this review was not applicable (Haveman 2014). However, to comply with Cochrane MECIR standards, we are including them below.

\section{Selection of studies}

After applying the search strategy, two review authors will independently identify studies meeting the inclusion criteria for this review. We will resolve discrepancies between review authors by discussion. If we cannot reach consensus, we will achieve final resolution using a third-party arbitrator. We will obtain the complete article of any study that seems to meet the inclusion criteria, in accordance with the title

High-dose chemotherapy followed by autologous haematopoietic cell transplantation for children, adolescents, and young adults with 16 
or the abstract, or both. We will produce a Characteristics of included studies table, and include detailed information for each study. We will clearly state details of the reasons for exclusion of any study considered for the review in the Characteristics of excluded studies table. We will include a PRISMA flow diagram of the selection of studies in the review. If there are multiple reports of the same study, we will use the most recent report as the primary publication; we will check the other available reports for data not reported in the primary publication.

\section{Data extraction and management}

Two review authors will independently extract data, using standardised forms. We will resolve discrepancies between review authors by discussion. If we cannot reach consensus, we will achieve final resolution using a third-party arbitrator. We will extract data on the characteristics of participants (e.g. age, gender, and other known risk factors in participants (tumour volume, primary metastatic disease, time of relapse after primary diagnosis, type of relapse and sites of metastases, response to second-line therapy)), interventions, outcome measures, study design, length of follow-up, details of funding sources, and declaration of interests for each included study.

\section{Assessment of risk of bias in included studies}

Two review authors will independently assess the risk of bias in included studies (i.e. selection bias, performance bias, detection bias (for each outcome separately), attrition bias (for each outcome separately), reporting bias, and other bias). We will use the risk of bias items and definitions of low risk of bias, unclear risk of bias, and high risk of bias as described in the module of the Childhood Cancer Group (Module CCG), which are based on the Cochrane Handbook for Systematic Reviews of Interventions (Higgins 2011). We will resolve discrepancies between review authors by discussion. If we cannot reach consensus, we will achieve final resolution using a third-party arbitrator. We will take into account the risk of bias in included studies in the interpretation of the review's results.

\section{Measures of treatment effect}

We will analyse dichotomous variables using risk ratios (RR). We will analyse survival using hazard ratios (HR). We will use Parmar's method if HRs have not been explicitly presented in the study (Parmar 1998). We will present all results with the corresponding $95 \%$ confidence interval $(\mathrm{Cl})$.

\section{Dealing with missing data}

When relevant data regarding study selection, data extraction, and risk of bias assessment are missing, we will attempt to contact the study authors to retrieve the missing data. We will extract data by the allocated intervention, irrespective of compliance with the allocated intervention, in order to allow an intention-to-treat analysis. If this is not possible, we will state this, and we will perform an as treated analysis.

\section{Assessment of heterogeneity}

We will assess heterogeneity both by visual inspection of the forest plots, and by a formal statistical test for heterogeneity (i.e. the $I^{2}$ statistic). In the absence of significant heterogeneity $\left(I^{2}\right.$ less than $\left.50 \%\right)$, we will use a fixed-effect model for the estimation of treatment effects (Higgins 2011). Otherwise, we will explore possible reasons for the occurrence of heterogeneity, and take appropriate measures, such as using a random-effects model.

\section{Assessment of reporting biases}

In addition to evaluating reporting bias as described in the Assessment of risk of bias in included studies section, we will assess reporting bias by constructing a funnel plot, when there are a sufficient number of included studies (i.e. at least 10 studies included in a metaanalysis). When there are fewer studies, the power of the test is too low to distinguish chance from real asymmetry (Higgins 2011).

\section{Data synthesis}

We will enter data into Cochrane's Review Manager 5 software, and undertake analyses according to the guidelines in the Cochrane Handbook for Systematic Reviews of Interventions (Higgins 2011; Review Manager 2020). We will include outcome measures only if it was the intention of the study to perform the necessary assessments in all randomised participants (i.e. not only optional, or only performed in some centres). When the results of a particular outcome measure are available for less than $50 \%$ of the participants of a study, due to the associated high risk of attrition bias, we will not report the results of this outcome measure. We will pool results only if both treatment groups are comparable, including the definition of outcomes used. We will provide a descriptive summary for studies for which pooling of results is not possible. We do not expect multi-arm studies (i.e. including more than two treatment groups); however, if we include these studies, we will take appropriate measures as described in the Cochrane Handbook for Systematic Reviews of Interventions (Higgins 2011). We will analyse historical controlled clinical trials separately. We will analyse studies that compare immunotherapy plus high-dose chemotherapy with autologous haematopoietic cell transplantation.

For each comparison, we will prepare a summary of findings table, using GRADEpro GDT software to calculate absolute effects, and the certainty of the evidence for each outcome (GRADEpro GDT). Two review authors will independently assess the certainty of the evidence, which we will rate as very low, low, moderate, or high according to the five GRADE considerations (i.e. study limitations, inconsistency, indirectness, imprecision, and publication bias), described in the Cochrane Handbook for Systematic Reviews of Interventions (Higgins 
2011). For each comparison, we will include evidence for the following outcomes: event-free survival, overall survival, quality-adjusted survival, toxicity, and progression-free survival.

\section{Subgroup analysis and investigation of heterogeneity}

We will not perform subgroup analyses.

\section{Sensitivity analysis}

For all outcomes for which pooling is possible, we will perform sensitivity analyses for all risk of bias criteria separately. We will exclude studies with a high risk of bias or unclear risk of bias, and compare the results of studies with a low risk of bias, with the results of all available studies.

\section{N DEX TERMS}

\section{Medical Subject Headings (MeSH)}

Antineoplastic Combined Chemotherapy Protocols [therapeutic use]; *Bone Neoplasms [drug therapy]; *Hematopoietic Stem Cell Transplantation; *Sarcoma, Ewing [drug therapy]; Transplantation, Autologous

\section{MeSH check words}

Adolescent; Child; Humans; Young Adult 